\title{
La regulación audiovisual en el Sistema Interamericano de Derechos Humanos y los desafíos de la digitalización
}

\author{
Ikus-entzunezkoen erregulazioa \\ Giza Eskubideen Sistema Inter-Amerikarrean \\ eta digitalizazioaren erronkak
}

\section{The audiovisual regulation in the Inter-American Human Rights System and the challenges of the digitalization}

\section{Fernando Krakowiak ${ }^{1}$}

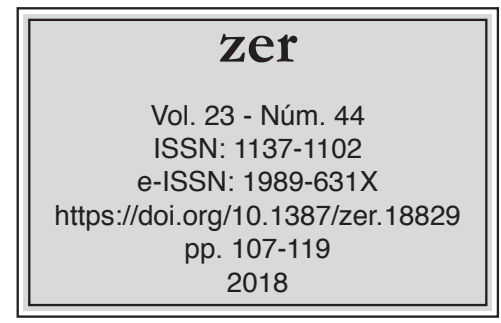

Recibido el 17 de noviembre de 2017, aceptado el 8 de marzo de 2018.

\section{Resumen}

El artículo analiza las recomendaciones del Sistema Interamericano de Derechos Humanos (SIDH) para la regulación de la concentración de la propiedad en la radiodifusión y el modelo regulatorio en el que se referencian. La hipótesis es que en el SIDH predomina una concepción intervencionista que fundamenta la protección de la libertad de expresión desde su dimensión individual y también social. Esa concepción es la que permite reivindicar la elaboración de normas destinadas a prevenir desde el Estado la concentración de mercado para garantizar el pluralismo y la diversidad. Además, se trabaja sobre los desafíos que le plantean a esa regulación los nuevos procesos de digitalización de la industria audiovisual.

Palabras clave: Latinoamérica; regulación; medios de comunicación; concentración; digitalización.

\section{Laburpena}

Artikuluak Giza Eskubideen Sistema Inter-Amerikarrak (SIDH) irratigintzako jabetza-kontzentrazioaren erregulazioari buruz eta hari erreferentzia egiten dion erregulazio-ereduari 
buruz emandako gomendioak aztertzen ditu. Hipotesia da SIDHen baitan ikuspegi interbentzionista dela nagusi. Oinarri hartzen du adierazpen-askatasunaren babesa, maila indibidualetik eta gizarte-mailatik. Ikuspegi horren bidez, aldarrikatzen du merkatu-kontzentrazioa saihestera bideratutako arauak egin behar direla Estatutik, aniztasuna eta dibertsitatea bermatzeko. Horrez gain, ikus-entzunezko industriaren digitalizazio-prozesu berriek erregulazio horri planteatzen dizkioten erronkak lantzen ditu.

Gako-hitzak: Latinoamerika; erregularizazioa; komunikabideak; kontzentrazioa; digitalizazioa.

\section{Summary}

The article analyses the recommendations of the Inter-American Human Rights System (IAHRS) for the regulation of the ownership concentration in broadcasting and the regulatory model these recommendations refer to. The hypothesis is that within the IAHRS prevails an interventionist conception that justifies the protection of freedom of speech not only from the individual dimension, but also from the social one. Such conception allows to defend the making of norms aimed at preventing from the part of the State the concentration of the market in order to ensure pluralism and diversity. Besides, it is also analysed the challenges posed by the new process of digitalization to such regulations.

Keywords: Latin America; regulation; media; concentration; digitalization. 


\section{Introducción}

El Sistema Interamericano de Derechos Humanos (SIDH) es un mecanismo de promoción y protección de derechos humanos a través de una serie de instrumentos jurídicos sancionados por los países que integran la Organización de los Estados Americanos (OEA), sistema mayor con el que interactúa, en el cual se apoya y con el que se complementa. Dispone de dos órganos para supervisar y hacer cumplir esos derechos: la Comisión Interamericana de Derechos Humanos (CIDH) y la Corte Interamericana de Derechos Humanos (Corte IDH),

Entre los derechos tutelados por el SIDH están incluidos la libertad de expresión y el derecho a la información. Este sistema sienta jurisprudencia sobre cómo diseñar e instrumentar políticas nacionales de comunicación destinadas a preservar esos derechos. Por lo tanto, suele ser un espacio de disputa y negociación permanente.

El objetivo de este artículo es analizar los tratados, declaraciones, sentencias, opiniones consultivas, informes de casos e informes anuales de relatorías del SIDH que refieren a la regulación de la concentración de la propiedad de medios de comunicación, poniendo especial énfasis en el sector audiovisual, para precisar si esos documentos se inscriben en un modelo regulatorio de mercado o intervencionista.

El relevamiento incluye la Declaración Americana de los Derechos y Deberes del Hombre, la Convención Americana sobre Derechos Humanos, la Declaración de Principios sobre Libertad de Expresión, el documento Antecedentes e Interpretación de la Declaración de Principios sobre Libertad de Expresión, las Declaraciones de la Relatoría de Libertad de Expresión, los veinte informes anuales que elaboró la Relatoría de Libertad de Expresión desde su creación, y las sentencias y opiniones consultivas de la Corte IDH referidas a medios de comunicación. ${ }^{2}$

La hipótesis de este trabajo es que en el SIDH predomina una concepción regulatoria intervencionista que fundamenta la protección de la libertad de expresión no solo desde su dimensión individual -el derecho de cada persona a difundir sus opiniones por cualquier medio- sino también desde su dimensión social -necesidad de todos los ciudadanos de recibir información y opiniones diversas-. Esa concepción es la que permite reivindicar la elaboración de normas destinadas a prevenir desde el Estado la concentración de mercado para garantizar el pluralismo y la diversidad de voces, condiciones que son consideradas esenciales por el SIDH para el adecuado funcionamiento de una sociedad democrática.

En la primera parte del trabajo se describen los dos grandes modelos que regulan la radiodifusión, el intervencionista y el de mercado, y se identifican los valores en conflicto y los conceptos clave en torno a los que se organizan esos modelos a partir del relevamiento de bibliografía dedicada a su análisis.

\footnotetext{
2 Entre 1979, año de su conformación, y 2017, la Corte IDH emitió 24 opiniones consultivas, pero solo la $\mathrm{OC} \mathrm{N}^{\circ} 5$ (1985) y la OC $\mathrm{N}^{\circ} 7$ (1986) se refieren a medios de comunicación, mientras que los efectos de la concentración de la propiedad de medios sobre la libertad de expresión se analizan en la OC $\mathrm{N}^{\circ}$ 5. A su vez, hay 21 sentencias de la Corte IDH que refieren a la libertad de expresión, pero los efectos de la concentración en la propiedad de medios de comunicación son analizados en los casos "Kimel vs. Argentina" (2008), "Fontevecchia D’Amico vs. Argentina" (2011) y "Granier y otros (Radio Caracas Venezuela) vs. Venezuela" (2015).
} 
En la segunda parte se pone el foco en el corpus seleccionado y con el andamiaje conceptual desplegado en el punto anterior se busca determinar en qué modelo regulatorio se referencian los documentos del SIDH. La metodología consiste en relevar esos documentos para identificar si las recomendaciones se inscriben dentro del modelo intervencionista, que privilegia criterios políticos y socioculturales para la defensa de la pluralidad y la diversidad, o dentro del modelo de mercado que equipara el pluralismo a la libertad de elección y busca minimizar las regulaciones gubernamentales para no interferir con esa libertad.

Por último, en la tercera parte se analiza cómo los procesos de digitalización y convergencia audiovisual han comenzado a desafiar el modelo regulatorio que se desprende de los documentos del SIDH a partir de una serie de transformaciones que atraviesan a la radiodifusión. El objetivo de este punto es apenas dejar planteada la aparición de una agenda emergente como modo de anticiparse a las tensiones que empiezan a poner en crisis la concepción regulatoria predominante en el SIDH.

\section{Modelos regulatorios de la radiodifusión}

El debate de ideas que se produjo durante la Ilustración y el modelo informativo resultante posibilitaron la expansión de los principios de libertades económicas y civiles sobre los que se fundó la Revolución Francesa. La Declaración de los Derechos del Hombre y el Ciudadano del 27 de agosto de 1789 proclamó la libre comunicación de los pensamientos y las opiniones como uno de los derechos individuales más preciados del hombre, formulación que luego se plasmaría normativamente en las sucesivas constituciones de las democracias liberales como libertad de expresión, de opinión o de prensa (González Gartland et al, 1993: 75-85). Es a partir de este período cuando la intervención del Estado sobre los medios empieza a ser caracterizada con mayor énfasis como negativa y restrictiva de la libertad de expresión. De este modo, se buscaba limitar su accionar censor, característico de los regímenes absolutistas previos.

Durante el siglo XIX, con la invención del telégrafo eléctrico, el teléfono y las tecnologías inalámbricas surge una nueva dimensión regulatoria caracterizada por leyes que por lo general se desprenden de acuerdos internacionales relativos a requerimientos técnicos, como la asignación de espectro radioeléctrico o el establecimiento de estándares comunes de transmisión, dimensión que se va a consolidar en el siglo XX con la aparición de la radio y la televisión. A su vez, estos medios tendrán mayores restricciones en cuanto a los contenidos de los que rigen para la prensa escrita, debido a consideraciones políticas, sociales y culturales, con ejemplos más flexibles (Estados Unidos) y más estrictos (Europa).

La libertad de expresión extendida a los medios masivos de comunicación se promueve en el siglo XIX como libertad de prensa, pues los únicos medios que existían por entonces eran los gráficos y solo accedían al ejercicio de esa libertad quienes contaban con los recursos materiales para tener un medio propio. A comienzos del siglo XX algunos derechos propios de la libertad de prensa se le extienden también, a través de los estatutos profesionales, a quienes trabajan en una empresa informativa y dedican su esfuerzo a la búsqueda y la transmisión de información. Sin embargo, la ampliación definitiva del derecho a la libertad de prensa va a llegar a mediados 
del siglo XX con la Declaración Universal de los Derechos del Hombre del 10 de diciembre de 1948, que no tiene fuerza jurídica, sino que solo cuenta como declaración principista capaz de operar como una obligación moral. De este modo, el derecho a la información es el resultado de un devenir histórico que comienza por reconocer derechos a quienes son propietarios de las estructuras informativas, luego a quienes trabajan bajo la dependencia de aquellos y, finalmente, a todos los hombres (Loreti, 1995: 17).

Lo que justificó este cambio fue en parte una creciente concentración de la propiedad, que ya había comenzado a tomar forma a fines del siglo XIX en el mercado de medios gráficos y se agudizó luego con la aparición de la radio y la televisión. La concentración, impulsada por lógicas comerciales que promueven las economías de escala, elevó las barreras de entrada y restringió la pluralidad de voces, dejando claro que no bastaba con la no intervención del Estado para garantizar el derecho a la libertad de expresión, sino que paradójicamente iba a comenzar a ser necesaria su intervención a través de la definición de políticas de comunicación para garantizarlo. La libertad de expresión entendida como un derecho individual comienza así a rivalizar con otra concepción que la considera como un derecho público, como un "instrumento de autodeterminación colectiva" (Fiss, 1997). Desde entonces, conviven dos grandes modelos regulatorios: el de mercado y el intervencionista (Venture1li, 1998; Van Cuilenburg y McQuail, 2003; Klimkiewicz, 2009).

En el modelo de mercado, el pluralismo se equipara a la libertad de elección y las regulaciones gubernamentales son mínimas para no interferir con esa libertad, limitándose fundamentalmente a sancionar abusos de posición dominante y conductas anticompetitivas. En este caso, la distorsión se identifica con el abuso de la posición dominante porque la concentración en sí misma no es caracterizada como algo negativo e incluso se afirma que no afecta la diversidad del contenido ofrecido por los medios de comunicación (Compaine y Gomery, 2000; Groseclose y Milo, 2005; Thierer, 2005; Della Vigna y Kaplan, 2006).

El segundo modelo, en cambio, se basa en una interpretación del pluralismo entendido como la convivencia de distintos puntos de vista políticos y culturales que es necesario garantizar a través de una intervención estatal que prevenga la concentración de la propiedad de los medios y no opere sólo sobre sus consecuencias no deseadas (Murdock y Golding, 1973; Bagdikian, 1983; Miguel, 1994; Bustamante, 1994; Herman y McChesney, 1997; Doyle, 2002; Mastrini y Becerra, 2006; Mastrini, 2014).

De este modo, de un lado se ubica la metáfora del "libre mercado de ideas", donde los límites y criterios son establecidos por los principios de la competencia y la elección del consumidor, y del otro lado una perspectiva neo-habermasiana que recupera el concepto de esfera pública como marco de referencia en el cual los distintos actores deliberan de manera democrática y racional, haciendo valer libertades fundamentales que es necesario preservar. Como destacan Van Cuilenburg y McQuail, en ambos casos el objetivo general que se promueve es el interés público, pero en el modelo de mercado predomina la búsqueda del bienestar económico asociado a valores como eficiencia, beneficio, empleo, innovación e interconexión, mientras que en el modelo intervencionista se apunta al bienestar político, siendo el valor principal la libertad de expresión y publicación (Van Cuilenburg y McQuail, 2003). 
En el próximo punto se analiza cómo se plasma este debate entre el modelo de mercado liberal y el intervencionista estatal en las recomendaciones del SIDH referidas a la regulación de la concentración de la propiedad de los medios de comunicación, poniendo especial énfasis en el sector audiovisual.

\section{El derecho a la información en el SIDH. Interpretaciones y disputas}

En el continente americano, el primer antecedente de reconocimiento del derecho a la información lo constituyó la Declaración Americana de los Derechos y Deberes del Hombre aprobada por la IX Conferencia Internacional Americana realizada en Bogotá del 30 de marzo al 2 de mayo de 1948, donde también se dispuso la creación de la OEA. Fue el primer acuerdo internacional sobre derechos humanos, anticipándose incluso seis meses a la Declaración Universal de los Derechos del Hombre. ${ }^{3}$ En su artículo IV establece que "toda persona tiene derecho a la libertad de investigación, de opinión y de expresión y difusión del pensamiento por cualquier medio".

Luego sería el turno de la Convención Americana sobre Derecho Humanos (CADH), suscripta el 22 de noviembre de 1969 por los Estados miembro de la OEA y conocida como "Pacto de San José de Costa Rica"4. En lo que respecta a la libertad de expresión, en los tres primeros puntos del artículo 13 establece:

1. Toda persona tiene derecho a la libertad de pensamiento y de expresión. Este derecho comprende la libertad de buscar, recibir y difundir informaciones e ideas de toda índole, sin consideración de fronteras, ya sea oralmente, por escrito o en forma impresa o artística, o por cualquier otro procedimiento de su elección.

2. El ejercicio del derecho previsto en el inciso precedente no puede estar sujeto a previa censura sino a responsabilidades ulteriores, las que deben estar expresamente fijadas por la ley y ser necesarias para asegurar:

a). el respeto a los derechos o a la reputación de los demás, o

b). la protección de la seguridad nacional, el orden público o la salud o la moral públicas.

3. No se puede restringir el derecho de expresión por vías o medios indirectos, tales como el abuso de controles oficiales o particulares de papel para periódicos, de frecuencias radioeléctricas, o de enseres y aparatos usados en la difusión de información o por cualesquiera otros medios encaminados a impedir la comunicación y la circulación de ideas y opiniones.

\footnotetext{
3 IX Conferencia Internacional de los Estados Americanos: “Acta final; resolución XXX”, Bogotá, Colombia, Marzo 30 - mayo 2 de 1948.

${ }^{4}$ El Pacto de San José de Costa Rica constituye un tratado internacional abierto a la firma, ratificación o reserva de cualquier Estado miembro de la Organización de Estados Americanos (OEA). Entró en vigor el 18 de julio de 1978, al haber sido depositado el undécimo instrumento de ratificación por un Estado Miembro de la OEA. Al cierre de este trabajo (octubre de 2017), había sido ratificado por 25 Estados Americanos, con distintos tipos de reservas en cada caso.
} 
La Convención le asignó en su artículo 33 a dos organismos dependientes de la OEA el objetivo de garantizar el cumplimiento de los derechos esenciales en el continente americano: La Comisión Interamericana de Derechos Humanos (CIDH), que había sido prevista en la Carta de la Organización de la OEA de 1948, que se crearía en 1959 y que funcionaba desde 1960, y la Corte Interamericana de Derechos Humanos (Corte IDH), tribunal que se estableció recién en 1979, un año después de que la Convención entró en vigencia. ${ }^{5} \mathrm{La}$ CIDH tiene la función principal de promover la observancia y la defensa de los derechos humanos (artículo 41 de la CADH), mientras que la Corte IDH tiene competencia para conocer cualquier caso relativo a la interpretación y aplicación de la Convención, siempre que los Estados partes en el caso hayan reconocido su competencia (artículo 62 de la CADH) ${ }^{6}$

Un paso clave por parte de la Corte IDH para fundamentar la protección de la libertad de expresión fue la Opinión Consultiva $N^{\circ} 5$ del 13 de noviembre de 1985 referida a una consulta sobre colegiación obligatoria de periodistas y su relación con la CADH, donde el organismo distingue entre la dimensión individual y social de la libertad de expresión. ${ }^{7}$ En el párrafo 30 de esa opinión establece que cuando la CADH señala en su artículo 13 que la libertad de pensamiento y expresión "comprende la libertad de buscar, recibir y difundir informaciones e ideas de toda índole..." lo que está haciendo es establecer literalmente que quienes están bajo la protección de la Convención tienen no sólo el derecho y la libertad de expresar su propio pensamiento, sino también el derecho y la libertad de buscar, recibir y difundir informaciones e ideas:

Cuando se restringe ilegalmente la libertad de expresión de un individuo, no sólo es el derecho de ese individuo el que está siendo violado, sino también el derecho de todos a 'recibir' informaciones e ideas, de donde resulta que el derecho protegido por el artículo 13 tiene un alcance y un carácter especiales. Se ponen así de manifiesto las dos dimensiones de la libertad de expresión. En efecto, ésta requiere, por un lado, que nadie sea arbitrariamente menoscabado o impedido de manifestar su propio pensamiento y representa, por tanto, un derecho de cada individuo; pero implica también, por otro lado, un derecho colectivo a recibir cualquier información y a conocer la expresión del pensamiento ajeno (Corte IDH, OC 5/85, párrafo 30).

\footnotetext{
5 El 22 de mayo de 1979 los Estados Partes en la Convención Americana eligieron, durante el Séptimo Período Extraordinario de Sesiones de la Asamblea General de la OEA, a los primeros jueces que integraron la Corte Interamericana. La primera reunión de la Corte se celebró el 29 y 30 de junio de 1979 en la sede de la OEA en Washington.

${ }^{6}$ La Corte IDH no fue establecida en la Carta de la Organización de la OEA sino en la CADH. Por lo tanto, no todos los Estados miembros de la OEA están sometidos a su jurisdicción sino sólo aquellos que han ratificado la CADH y han reconocido además su competencia.

7 Corte IDH, La Colegiación Obligatoria de Periodistas (arts. 13 y 29 Convención Americana sobre Derechos Humanos). Opinión Consultiva OC-5/85 del 13 de noviembre de 1985. Serie A No. 5.
} 
La evolución del derecho a la libertad de expresión muestra el establecimiento de una nueva concepción que privilegia los derechos sociales sin por ello desmerecer las libertades individuales. La diferencia es que el respeto por las libertades individuales por parte del Estado consiste fundamentalmente en abstenerse de impedir el ejercicio de las mismas, salvo en los casos en que esa libertad atente contra el derecho de terceros, mientras que la concepción de derechos sociales engloba el respeto de las libertades individuales, pero al mismo tiempo lo trasciende y exige una protección activa por parte del Estado. Como señala Owen Fiss, "el Estado puede ser opresor, pero también puede constituir una fuente de libertad (...) Este punto de vista -inquietante para algunos- descansa en una serie de premisas. Una de ellas se refiere al impacto que las concentraciones privadas de poder tienen sobre nuestra libertad; a veces se necesita al Estado para contrarrestar estas fuerzas" (Fiss, 1999:14).

El reconocimiento de los derechos sociales deriva en la correlativa existencia de deberes no sólo para con el individuo considerado aisladamente sino como integrante de la sociedad con el objetivo de garantizar un verdadero intercambio de ideas que enriquezca el debate público a partir del acceso igualitario de todos los individuos y grupos a los medios de comunicación:

En principio la libertad de expresión requiere que los medios de comunicación social estén virtualmente abiertos a todos sin discriminación, o, más exactamente, que no haya individuos o grupos que, a priori, estén excluidos del acceso a tales medios, exige igualmente ciertas condiciones respecto de éstos, de manera que, en la práctica, sean verdaderos instrumentos de esa libertad y no vehículos para restringirla (Corte IDH, OC 5/85, párrafo 34)

En lo que refiere ya específicamente a la concentración de la propiedad en el mapa de los medios y su posible impacto en la reducción de la pluralidad, la Corte IDH advierte que ya no basta con garantizar el derecho a la libertad de prensa, sino que hace falta intervenir para garantizar un proceso democrático de comunicación que comprenda al conjunto de la sociedad:

La Libertad de expresión se puede ver también afectada sin la intervención directa de la acción estatal. Tal supuesto podría llegar a configurarse, por ejemplo, cuando por efecto de la existencia de monopolios u oligopolios en la propiedad de los medios de comunicación, se establecen en la práctica "medios encaminados a impedir la comunicación y la circulación de ideas y opiniones". (Corte IDH, OC 5/85, párrafo 56)

De este modo, la Corte IDH deja en claro que por más que exista el derecho a difundir informaciones e ideas es inadmisible aceptar la conformación de monopolios ya que si bien estos ejercen su derecho a la libertad de expresión, al mismo tiempo están violando el derecho de los demás ciudadanos a acceder a una diversidad de ideas 
y opiniones. Desde este punto de vista, la promoción de normas para garantizar el pluralismo en los medios de comunicación es un requisito previo para que se cumpla el derecho humano a la libertad de expresión.

A su vez, en octubre de 1997 la CIDH creó una Relatoría Especial para la Libertad de Expresión como una oficina permanente e independiente encargada de estimular la defensa de la libertad de pensamiento y de expresión para de ese modo ayudar a consolidar y desarrollar los sistemas democráticos de la región y proteger los demás derechos humanos. En respuesta al mandato encomendado con la creación de la Relatoría para la Libertad de Expresión, este organismo trabajó en la elaboración de un proyecto de Declaración de Principios sobre Libertad de Expresión que la CIDH aprobó en octubre de 2000 y que debía servir para interpretar el alcance del artículo 13 de la CADH. La Declaración incluye trece principios con previsiones específicas que los Estados de la región deben atender, entre los cuales el principio 12 refiere específicamente a la regulación de la concentración de la propiedad de los medios de comunicación:

Los monopolios u oligopolios en la propiedad y control de los medios de comunicación deben estar sujetos a leyes antimonopólicas por cuanto conspiran contra la democracia al restringir la pluralidad y diversidad que asegura el pleno ejercicio del derecho a la información de los ciudadanos. En ningún caso esas leyes deben ser exclusivas para los medios de comunicación. Las asignaciones de radio y televisión deben considerar criterios democráticos que garanticen una igualdad de oportunidades para todos los individuos en el acceso a los mismos (CIDH, Declaración de Principios sobre Libertad de Expresión, principio 12)

En la interpretación de los principios de la Declaración, la CIDH incluso va más allá al dejar en claro por qué los medios de comunicación no deben estar controlados por un reducido grupo de personas:

En la sociedad actual, los medios de comunicación masiva, como la televisión, radio y prensa, tienen un innegable poder en la formación cultural, política, religiosa, etc. de todos los habitantes. Si estos medios son controlados por un reducido número de individuos, o bien por sólo uno, se está, de hecho, creando una sociedad en donde un reducido número de personas, ejercen el control sobre la información, y directa o indirectamente, la opinión que recibe el resto de las personas. Esta carencia de pluralidad en la información es un serio obstáculo para el funcionamiento de la democracia (CIDH, Antecedentes e interpretación de la Declaración de Principios, principio 12, punto 55).

En aplicación de estos principios, la Relatoría Especial para la Libertad de Expresión de la OEA ha venido advirtiendo en sus declaraciones e informes anuales, en 
algunos casos junto a relatores de otros organismos internacionales, sobre la necesidad de prevenir la concentración de la propiedad de los medios de comunicación por ser una amenaza para el pluralismo y la diversidad de voces. En una declaración conjunta del 20 de noviembre de 2001 se advirtió que "deben adoptarse medidas efectivas para evitar una concentración indebida de la propiedad en los medios de difusión". ${ }^{8}$ En otra declaración conjunta del 10 de diciembre de 2002 se dejó constancia de "la amenaza que plantea la creciente concentración de la propiedad de los medios de prensa y los medios de comunicación, en particular para la diversidad y la independencia editorial""

A su vez, en su Informe Anual de 2002 la Relatoría incluyó por primera vez un capítulo referido a la libertad de expresión y los medios comunitarios donde no solo contempla el derecho de los que ya tienen medios de comunicación para expresarse sino también el derecho de las organizaciones comunitarias que tienen dificultades para acceder a los medios. A raíz de ello en el párrafo 43 de ese informe establece:

\begin{abstract}
Dada la importancia que pueden tener estos canales de ejercicio de la libertad de expresión comunitario, resulta inadmisible el establecimiento de marcos legales discriminatorios que obstaculizan la adjudicación de frecuencias a radios comunitarias.
\end{abstract}

Otro aporte clave es el que la Relatoría incorpora en su Informe Anual de 2004 cuando en el párrafo 94 interpreta la restricción expresada en el principio 12 de la Declaración de Principios sobre Libertad de Expresión que dice que en ningún caso las leyes antimonopólicas deben ser diseñadas de modo exclusivo para regular a los medios de comunicación. Eso impediría, por ejemplo, la existencia de una ley sectorial que ponga límites a la concentración en el mercado audiovisual, pero la Relatoría deja en claro que se puede avanzar en esa dirección siempre y cuando no se busque afectar la libertad de prensa:

La Relatoría considera que el marco del derecho a la competencia en muchas ocasiones puede resultar insuficiente, particularmente en cuanto a la asignación de frecuencias radioeléctricas. No se impide entonces la existencia de un marco regulatorio antimonopólico que incluya normas que garanticen la pluralidad atendiendo la especial naturaleza de la libertad de expresión. En todo caso, a la luz del principio 12 los Estados no deben adoptar normas especiales bajo la apariencia de normas antimonopólicas para los medios de

\footnotetext{
8 Declaración Conjunta sobre la libertad de expresión en el nuevo siglo firmada por el Relator Especial de las Naciones Unidas sobre la Libertad de Opinión y Expresión, el Representante de la sobre la Libertad de los Medios de Comunicaciones y el Relator Especial para la Libertad de Expresión de la OEA, el 20 de noviembre de 2001

9 Declaración Conjunta sobre libertad de expresión y administración de justicia, comercialización y libertad de expresión y difamación penal firmada por firmada por el Relator Especial de las Naciones Unidas sobre la Libertad de Opinión y Expresión, el Representante de la sobre la Libertad de los Medios de Comunicaciones y el Relator Especial para la Libertad de Expresión de la OEA, 10 de diciembre de 2002.
} 
comunicación que en realidad tienen como propósito y efecto la restricción de la libertad de expresión.

La propia Corte IDH reconoció en la sentencia del "Caso Kimel vs. Argentina" que la libertad de expresión no es un derecho absoluto ${ }^{10} \mathrm{y}$, como tal, admite reglamentaciones y restricciones. Además, en dicha resolución dejó en claro que el Estado debe impulsar el pluralismo informativo:

El Estado no sólo debe minimizar las restricciones a la circulación de la información sino también equilibrar, en la mayor medida de lo posible, la participación de las distintas informaciones en el debate público, impulsando el pluralismo informativo. En consecuencia, la equidad debe regir el flujo informativo (Corte IDH, Caso Kimel vs. Argentina, párrafo 57). ${ }^{11}$

A su vez, en la sentencia del "Caso Granier y otros vs. Venezuela" remarcó la obligación estatal de impulsar leyes y políticas públicas que garanticen el pluralismo:

Los Estados están internacionalmente obligados a adoptar las medidas que fueren necesarias "para hacer efectivos" los derechos y principios establecidos en la Convención, como se estipula en el artículo 2 de dicho instrumento interamericano, para lo cual deberán establecer leyes y políticas públicas que garanticen el pluralismo de medios o informativo en las distintas aéreas comunicacionales, tales como, por ejemplo, la prensa, radio, y televisión (Corte IDH, Caso Granier y otros vs. Venezuela, párrafo 145).

El marco general que establece las condiciones para que la regulación de un Estado sea legítima está determinado por los incisos 2, 3, 4 y 5 del artículo 13 de la CADH. Además, la jurisprudencia del sistema identifica tres condiciones específicas: (1) la limitación debe haber sido definida en forma precisa y clara a través de una ley formal y material; (2) la limitación debe estar orientada al logro de objetivos imperiosos autorizados por la Convención Americana; y (3) la limitación debe ser necesaria en una sociedad democrática para el logro de los fines imperiosos que se buscan; idónea para lograr el objetivo imperioso que pretende lograr; y estrictamente proporcional a la finalidad perseguida. ${ }^{12}$

\footnotetext{
${ }^{10}$ Corte IDH, Caso Kimel Vs. Argentina. Fondo, Reparaciones y Costas. Sentencia de 2 de mayo de 2008 Serie C, No. 177, párrafo 54.

${ }^{11}$ La Corte IDH reiteró esta postura en el párrafo 45 de la sentencia "Caso Fontevecchia y D`Amico vs. Argentina" del 29 de noviembre de 2011 y en el párrafo 144 de la sentencia "Caso Granier y otros vs. Venezuela" del 22 de junio de 2015.

${ }^{12}$ CIDH. Informe Anual 2008. Volumen II: Informe Anual de la Relatoría Especial para la Libertad de Expresión, pp. 135-136.
} 
En la Declaración sobre Diversidad en la Radiodifusión firmada el 12 de diciembre de 2007, el Relator Especial de la OEA sobre Libertad de Expresión recomendó explícitamente, junto a relatores de otros organismos internacionales ${ }^{13}$, impulsar leyes antimonopólicas para prevenir la concentración indebida de medios de comunicación:

En reconocimiento de la particular importancia que la diversidad de los medios de comunicación tiene para la democracia, para prevenir la concentración indebida de medios de comunicación o la propiedad cruzada de los mismos, ya sea horizontal o vertical, se deben adoptar medidas especiales, incluyendo leyes anti-monopólicas. Tales medidas deben implicar el cumplimiento de estrictos requisitos de transparencia sobre la propiedad de los medios de comunicación a todos los niveles. Además deben involucrar un monitoreo activo, el tomar en cuenta la concentración de la propiedad, en caso que sea aplicable, en el proceso de concesión de licencias, el reporte con antelación sobre grandes combinaciones propuestas, y la concesión de autoridad para evitar que tales combinaciones entren en vigor.

Pese a la amplia jurisprudencia reseñada del SIDH, las leyes sectoriales nacionales que buscan ponerle límites a la concentración de la propiedad en los distintos países de la región siguen siendo resistidas por los grandes medios de comunicación y las asociaciones que los agrupan, quienes identifican cualquier tipo de regulación específica que busque limitarlos con una amenaza a la libertad de expresión. Desde la visión liberal ven la intervención del Estado como el principal peligro a combatir e incluso relativizan que la concentración en la propiedad de los medios afecte la libertad de expresión al sostener que cierta "talla crítica" por parte de un medio le garantiza mayor independencia frente al poder estatal, siempre y cuando no se ponga en riesgo la libre competencia al hacer abuso de posición dominante o llevar adelante otro tipo de prácticas anticompetitivas. En el caso de que eso ocurra, la recomendación es que se apliquen las reglas generales de defensa de la competencia. De este modo, el sector de la comunicación es considerado un mercado como cualquier otro.

A partir de esta concepción es que se pone el foco en la necesidad de preservar la dimensión individual de la libertad de expresión, dejando de lado la dimensión social que se reivindica en el SIDH. La Asociación Internacional de Radiodifusión, organismo que agrupa asociaciones nacionales de radio y televisión privada de toda América, ha remarcado cada vez que tuvo la oportunidad que si bien la regulación de libre competencia debe propender a que ningún actor haga abuso de su posición dominante para impedir el surgimiento de otros medios el principio 12 de la Declaración de Principios sobre Libertad de Expresión aclara que en ningún caso las leyes antimonopólicas deben ser exclusivas para los medios de comunicación, relativizando o incluso ignorando la interpretación que ha hecho de ese principio la Relatoría

\footnotetext{
${ }^{13}$ La declaración también fue firmada por el Relator Especial de Naciones Unidas sobre Libertad de Opinión y de Expresión, el Representante de la OSCE sobre Libertad de los Medios de Comunicación y la Relatora Especial de la Comisión Africana de Derechos Humanos y de los Pueblos sobre Libertad de Expresión y Acceso a la Información.
} 
Especial para la Libertad de Expresión de la CIDH en su informe anual de $2004 \cdot{ }^{14} \mathrm{Se}$ remarca que los regímenes de licencias o autorizaciones sólo pueden aceptarse para el acceso a un recurso limitado como es el espectro radioeléctrico pero no como una opción de política de comunicación, pues si no responde a una restricción técnica constituiría una forma de censura. Es correcto legislar sobre el acceso a licencias o autorizaciones de uso del espectro, pero el regulador también está facultado para sancionar normas que a priori organicen de manera equitativa el acceso de los ciudadanos a los medios de comunicación y eso no constituye una práctica de censura en sí misma.

Damián Loreti y Luis Lozano sostienen en "El derecho a comunicar", por ejemplo, que el control de los oligopolios y monopolios en la comunicación no se debe limitar sólo a reglas generales de defensa de la competencia porque los productores de información y contenidos tienen dispositivos, fines y lógicas distintos a los de otros mercados (Loreti y Lozano, 2014: 172):

Es necesario debatir si las soluciones deben llegar a posteriori, mediante sanciones en los casos de prácticas predatorias, o ser reglas preventivas. Aquí tenemos un nuevo apartamiento del supuesto sentido común de la economía de los bienes y servicios. Los daños a la libertad de expresión, así como a los derechos humanos y a la democracia en general, no son reparables con dinero. Las distorsiones a la competencia y los negocios, sí.

El discurso liberal busca fortalecer el modelo regulatorio de mercado que apuesta a limitar la intervención del Estado a controles ex post, ya que así se aprovechan las ventajas de la economía de escala y se incentiva la innovación. El problema es que ese razonamiento constituye una política simplista que ve al Estado como una amenaza a la libertad de expresión que es necesario minimizar cuando, como se ha visto, el Estado también puede convertirse en una garantía de esa libertad.

\footnotetext{
${ }^{14}$ En la Audiencia Pública convocada por la Corte Suprema de Justicia de Argentina el 28 de agosto de 2013 para analizar la constitucionalidad de la ley de Servicios de Comunicación Audiovisual 26.522 de ese país, el doctor Lucas Sebastián Grossman, “amicus curiae” convocado por la parte actora (el Grupo Clarín), impugnó la ley por ser una norma antimonopólica exclusiva para los medios de comunicación y lo justificó citando el principio 12 de la Declaración de Principios sobre Libertad de Expresión. Allí relativizó la interpretación de ese principio realizada en el Informe Anual 2004 de la Relatoría al afirmar que, si bien en ese texto se remarca que las leyes de defensa de la competencia pueden resultar insuficientes en el caso de los medios de comunicación, la referencia es para la asignación de frecuencias radioeléctricas. Igual, por las dudas, aclaró después que "más allá de eso, este informe 2004, preparado por un joven pasante de la Relatoría, no puede reemplazar el análisis detallado de las normas y jurisprudencia de cada país de la región para determinar si la ley general en materia de competencia es suficiente o no para garantizar la libertad de expresión" (Versión taquigráfica, página 36). La referencia a "un joven pasante" se debe a que el capítulo del informe que hace referencia al impacto de la concentración en la propiedad de los medios fue preparado y redactado por Carlos J. Zelada, egresado de la maestría en derecho de la Universidad de Harvard, quien desarrolló la investigación durante su estadía como pasante en la Relatoría.
} 


\section{Desafíos regulatorios frente a la digitalización}

De los tratados, declaraciones e informes de relatoría del SIDH se desprenden, como se detalló en el punto anterior, varias recomendaciones que pueden inscribirse dentro del modelo intervencionista que privilegia criterios políticos y socioculturales para la defensa de la pluralidad y la diversidad por sobre pautas de libre mercado destinadas a incentivar las economías de escala y promover la innovación empresarial. No obstante, la postura liberal que promueve una regulación más laxa ha buscado ganar terreno durante los últimos años de la mano de la digitalización y la convergencia de las redes. El argumento es que la expansión de internet, la convergencia entre la radiodifusión y las telecomunicaciones, la posibilidad de multiplicar la oferta de señales con tecnologías de compresión digital, la proliferación de dispositivos para acceder y consumir contenidos audiovisuales y la reducción de los costos asociados a la producción de esos contenidos garantizan una mayor diversidad y pluralidad de voces y vuelven necesario flexibilizar las regulaciones. Uno de los máximos exponentes de estos planteos es Adam Thierer, quien sostiene abiertamente que las nuevas tecnologías de la comunicación han vuelto innecesaria la intervención del Estado para evitar la concentración (Thierer, 2005: 14).

No hay dudas de que la regulación del sector audiovisual enfrenta nuevos desafíos en un escenario donde la televisión programada por aire y unidireccional va perdiendo terreno frente al crecimiento de ofertas de contenidos que llegan por internet a través de plataformas que operan a escala global como Youtube, Netflix o HBO Go, las cuales ya no solo se ven en las computadoras sino también en los teléfonos móviles e incluso en televisores "inteligentes" que se conectan a la red. No obstante, otros autores advierten que esas innovaciones no garantizan por sí mismas la pluralidad y diversidad de contenidos.

Desde el punto de vista de los defensores del "libre mercado de las ideas", las normas que regulan la comunicación se deben flexibilizar porque constituyen restricciones que le ponen límites al mejor aprovechamiento empresario de las economías de escala en un escenario donde la pluralidad y diversidad de contenidos ya está garantizada por un incremento de la oferta a partir de la expansión de internet y las nuevas tecnologías de la comunicación (De Sola Pool, 1983; Rheingold, 1993; Dutton, 2007). William Dutton aseguró incluso que Internet es en este siglo el "Quinto Poder", en paralelo al papel que cumplió la prensa como Cuarto Poder desde el Siglo XVIII (Dutton, 2007:2). Si bien las innovaciones técnicas reseñadas plantean buenas perspectivas para un mayor flujo de información diversa y plural no hay una causalidad directa e inevitable entre esas innovaciones y el pluralismo informativo. No la hubo antes con otras innovaciones técnicas y no la hay ahora.

El desarrollo tecnológico comunicacional suele venir de la mano habitualmente de discursos que proyectan tendencias sociales observables a partir del despliegue de determinados dispositivos electrónicos, como si la posibilidad técnica garantizara por sí misma el hecho social. Como si el efecto de la tecnología fuera siempre el mismo, independientemente de quien lo controle y quien lo use. La sociedad de la información imaginada por el matemático estadounidense Norbert Wiener en Cybernetics or Control and Communication in the Animal and the Machine (1948) es un claro ejemplo de esta utopía generada en torno a la comunicación, que también se 
encuentra en la obra "Comprender los medios de comunicación” del filósofo canadiense Marshall McLuhan (1964) y que, luego de algunos altibajos, resurge desde fines de la década de 1980 con el desarrollo de internet, lo que lleva al teórico Philippe Breton a ironizar al afirmar que "nuestra modernidad es curiosamente conservadora: nuestro futuro es el de los años cuarenta" (Breton, 2000: 12).

Raymond Williams es uno de los teóricos que reflexiona sobre la relación entre política y tecnología a partir de la idea que postula a los usos sociales de la tecnología como la verdadera síntesis de su sentido. Lo que Williams sostiene es que la tecnología es, en primer lugar, el marco de conocimientos, tanto teóricos como prácticos, necesarios para el desarrollo de habilidades y aplicaciones (inventos técnicos) y, en segundo lugar, un marco de conocimientos y condiciones a partir del cual se preparan para su utilización. Desde esta perspectiva, la tecnología no es un producto de un proceso autónomo dirigido por ingenieros, aunque temporalmente pueda ser considerada de carácter autónomo, sino una cuestión social y cultural, que se desarrolla en concordancia con los fines buscados a partir de una gama amplia de posibilidades. Esto no quiere decir que no esté determinada por presiones reales y poderosas, pero ni la teoría ni la práctica de una determinada invención técnica es una causa necesaria o predictora (Williams (2011 [1974]: 164). Esa teoría y esa práctica pueden cambiar y ese cambio no dependerá de las propiedades del dispositivo en cuestión ni del carácter necesario de sus instituciones sino de la acción y la lucha social de los sujetos.

Por ese motivo, es necesario profundizar sobre los desafíos que la digitalización supone para los reguladores. Frente a la convergencia potencial de servicios sobre una o más redes, la clave pasa por establecer quién va a administrar esas redes, bajo qué reglas, quién va a hacer que esas reglas se cumplan y de qué manera. La necesidad de garantizar la neutralidad de la red aparece como uno de los principales desafíos para evitar conductas anticompetitivas en este nuevo escenario, pero desde ya no es lo mismo un mercado que traza una línea divisoria entre distribución y contenidos que otro mercado donde la falta de límites previos a la concentración de la propiedad de los medios de comunicación lleva a que el principal operador de la infraestructura sea a su vez uno de los principales productores de los contenidos audiovisuales que se distribuyen a través de esa infraestructura. El surgimiento y despliegue de Over The Top $(O T \& T)$, como Netflix o HBO Go, y de Operadores Móviles Virtuales (OMV) de telecomunicaciones, como Virgin, capaces de introducir más competencia al mercado, dependen de esas regulaciones.

La prestación de servicios audiovisuales a través de las redes de fibra o satélite exponen, al mismo tiempo, los límites de los Estados nacionales, para regular a empresas que operan a escala global y que tienen sus servidores muchas veces fuera del radio de acción del regulador. Qué hacer cuando los límites a la concentración se pueden aplicar sobre algunos jugadores, pero no sobre otros por falta de jurisdicción. "Una de las opciones que se presenta como más factible es separar la distribución de los contenidos, aunque para esto es preciso contar con mecanismos de decisión política que no solo atiendan a las necesidades de los principales grupos transnacionales de la comunicación”, advierte Mastrini (2014: 194)

Las transformaciones que se observan a partir de la digitalización y la convergencia, sin duda suponen nuevos desafíos regulatorios en pos de garantizar la 
diversidad y pluralidad, pero no constituyen necesariamente la solución para alcanzar ese objetivo, como pareciera desprenderse de los discursos que promueven una mayor desregulación.

\section{Conclusiones}

En los tratados, declaraciones, sentencias, opiniones consultivas e informes anuales de relatorías del SIDH que refieren a la regulación de la concentración de la propiedad de medios de comunicación en la radiodifusión predomina una concepción intervencionista que permite reivindicar la elaboración de normas destinadas a prevenir desde el Estado la concentración en la propiedad de los medios de comunicación para garantizar el pluralismo y la diversidad.

El principio 12 de la Declaración de Principios sobre Libertad de Expresión dice que las leyes antimonopólicas no deben ser exclusivas para los medios de comunicación poniendo en cuestión las normas que regulan el sector audiovisual, incluyendo los límites previos a la concentración de mercado. Sin embargo, la Corte IDH ha reivindicado explícitamente en la Opinión Consultiva 5/85 la intervención del Estado al hacer valer la dimensión social de la libertad de expresión, remarcando que la libertad y la diversidad deben ser principios rectores de la regulación de la radiodifusión, jurisprudencia que recuperó en las sentencias de los casos "Kimel vs. Argentina" (2008), "Fontevecchia y D'Amico vs. Argentina" (2011) y "Granier y otros vs. Venezuela" (2015). En el fallo "Granier y otros vs. Venezuela" remarcó incluso la obligación estatal de impulsar leyes y políticas públicas que garanticen el pluralismo.

Además, el informe de 2004 de la Relatoría Especial para la Libertad de Expresión relativiza la advertencia incluida en el principio 12 sobre las leyes antimonopólicas y declaraciones como la referida a la diversidad en la radiodifusión de 2007 recomiendan explícitamente prevenir la concentración indebida de la propiedad de los medios de comunicación con regulaciones destinadas a garantizar el pluralismo. Esto permite concluir que las recomendaciones emanadas del SIDH se inscriben mayoritariamente dentro del modelo intervencionista.

Ese conjunto de instrumentos jurídicos están siendo desafiados en los últimos tiempos por las transformaciones que implican los procesos de digitalización y convergencia y, fundamentalmente, por el auge de un discurso que deposita en las innovaciones técnicas una supuesta garantía de mayor pluralidad y diversidad de voces en los medios de comunicación, discurso funcional al modelo regulatorio de mercado, donde los límites y criterios son establecidos por los principios de la libre competencia y la elección del consumidor. La regulación del sector audiovisual enfrenta nuevos desafíos, pero la historia demuestra que las innovaciones técnicas no garantizan por sí mismas la pluralidad y diversidad de voces. Los efectos de la tecnología dependen de la intencionalidad que se le asigne. Por lo tanto, la clave, tanto antes como ahora, pasará por la discusión política y cultural sobre lo que se quiera para el sistema de medios de comunicación. 


\section{Referencias bibliográficas}

Bagdikian, B. (1983). The media monopoly. Boston: Bacon Press.

Breton, P. (2000). La utopía de la comunicación: el mito de la aldea global. Buenos Aires: Nueva Visión.

Bustamante, E. (1994). La concentración en la comunicación y la cultura. En VV.AA. (Ed.), Concentració i internacionalització dels Mitjans de Comunicació. Repercussions socials i culturals (pp. 11-26). Barcelona: Centre d'Investigació de la Comunicació.

Compaine, B. M., y Gomery, D. (2000). Who owns the media?: competition and concentration in the mass media industry (3rd ed.). Mahwah, N. J.: Erlbaum Associates.

Della Vigna, S., y Kaplan, E. (2006). The Fox News effect: Media bias and voting. Cambridge: National Bureau of Economic Research. Recuperado de http://www. nber.org/papers/w12169

Doyle, G. (2002). Media ownership. Londres: Sage.

Dutton, W. H. (2007). Through the Network (of Networks) - the Fifth Estate, Lectura inaugural, University of Oxford, 15 de octubre. Recuperado de https://papers. ssrn.com/sol3/papers.cfm?abstract_id=1134502

Fiss, O. (1997). Libertad de expresión y estructura social. México: Distribuciones Fontamara.

Fiss, O. (1999). La ironía de la libertad de expresión. Barcelona: Gedisa.

González Gartland, C.; Alén, L. y Esparis, R. (1993). Lecciones de derecho a la información y derecho de la información. Buenos Aires: Ediciones Colihue.

Groseclose, T., y Milo, J. (2005). A measure of media bias. Quarterly Journal of economics, cxx (4).

Herman, E. S., y Mcchesney, R. W. (1997). Los medios globales: los nuevos misioneros del capitalismo corporativo. Madrid: Cátedra.

Klimkiewicz, B. (2009). Is the Clash of rationalities Leading Nowhere? Media Pluralism in European Regulatory Policies. En Czepek, A.; Hellwig, M. Nowak, E. Press Freedom and Pluralism in Europe: Concepts and Conditions, Bristol: Intellect.

Loreti D. y Lozano L. (2014). El derecho a comunicar. Los conflictos en torno a la libertad de expresión en las sociedades contemporáneas. Buenos Aires: Siglo Veintiuno Editores.

Loreti, D. (1995). El derecho a la información. Buenos Aires: Paidós.

Mastrini, G. (2014). Las industrias culturales en Argentina. Tesis de doctorado, Universidad Complutense de Madrid. Recuperado de http://eprints.ucm.es/24687/1/ T35195.pdf

Mastrini, G., y Becerra, M. (2006). Periodistas y magnates: estructura y concentración de las industrias culturales en América Latina. Buenos Aires: Prometeo Libros.

Miguel, J. C. (1994). Los grupos multimedia. Estructura y estrategias en los medios europeos. Barcelona: Bosch.

Murdock, G., y Golding, P. (1973). For a political economy of mass communications. En R. Miliband \& J. Saville (Eds.), The Socialist Register (pp. 207-223). Londres: Merlin Press. 
Pool, de Sola, I. (1983). Technologies of Freedom. Cambridge, MA: Harvard Press, Belknap Press.

Rheingold, H. (1993). The Virtual Community, Homesteading on the Electronic Frontier. Massachusetts: Addison-Wesley.

Thierer, A. (2005). Media Myths: Making Sense of the Debate Over Media Ownership, Washington DC: Progress \& Freedom foundation.

Van Cuilenburg, J., y McQuail, D. (2003). Media policy paradigm shifts: towards a new communications policy paradigm. European Journal of Communication, 18(12), 181-207.

Venturelli, S. (1998). Liberalizing the European Media: Politics, Regulation and the Public Sphere. Oxford: Clarendon Press.

Williams, R. (1974). Televisión. Tecnología y Forma Cultural. Buenos Aires: Paidós. 